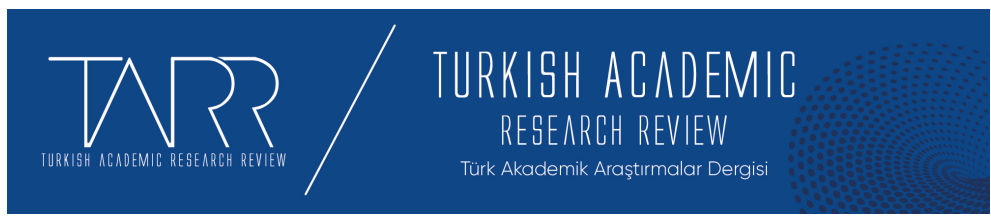

e-ISSN: 2602-2923

Yıl/Year: 2020 Cilt/Volume: 5 Sayı/Issue: 3

Balkanlar’da Bâbâgân Koluna Ait Bir XIX. Yüzyıl Bektâşî Erkânnâmesi

Baktashi Erkannamas Babagan School in the Balkans Beleong to 19. Century

\title{
Ali Albayrak
}

Doç. Dr., Akdeniz Üniversitesi İlahiyat Fakültesi Felsefe ve Din Bilimleri Bölümü Din Sosyoloji ABD, alialbayrak@akdeniz.edu.tr, Orcid: 0000-0003-0558-2612

\begin{tabular}{r|l} 
Makale Bilgisi & Article Information \\
Makale Türü - Article Type & Kitap İncelemesi / Book Review \\
Geliş Tarihi - Date Received & 6 Temmuz / July 2020 \\
Kabul Tarihi - Date Accepted & 25 Eylül / September 2020 \\
Yayın Tarihi - Date Published & 30 Eylül / September 2020 \\
Yayın Sezonu & Temmuz - Ağustos - Eylül \\
Pub Date Season & July - August - September
\end{tabular}

Atıf / Cite as: Albayrak, Ali, Balkanlar'da Bâbâgân Koluna Ait Bir XIX. Yüzyıl Bektâşî Erkânnâmesi/ Baktashi Erkannamas Babagan School in the Balkans Beleong to 19. Century. tarr: Turkish Academic Research Review, 5 (3), 438-455. doi: tarr.765174.

Intihal / Plagiarism: Bu makale, en az iki hakem tarafından incelenmiş ve intihal içermediği teyit edilmiştir. / This article has been reviewed by at least two referees and confirmed to include no plagiarism. https://dergipark.org.tr/tr/pub/tarr

Copyright (C) Published by Mehmet ŞAHIN Since 2016- Akdeniz University, Faculty of Theology, Antalya, 07058 Turkey. All rights reserved.

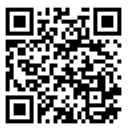

Turkish Academic Research Review - Türk Akademik Araştırmalar Dergisi 


\title{
Balkanlar'da Bâbâgân Koluna Ait Bir XIX. Yüzyıl Bektâşî Erkânnâmesi
}

\author{
Baktashi Erkannamas Babagan School in the Balkans Beleong to 19. \\ Century
}

\author{
Ali Albayrak \\ Ömer Faruk Teber \\ Balkanlar'da Bâbâgân Koluna Ait Bir XIX. Yüzyıl Bektâşî Erkânnâmesi \\ Ankara 2013, İlahiyat Yayınları, 1. Bask1, 169 s, ISBN: 978-605-4696-57-4
}

Hacı Bektaş Velî’yi pir olarak kabul edip, onun yolundan gidenlere Bektaşi adı verilmektedir. Bektaşiliğin XIII. Yüzyılda teşekkül etmeye başlayıp, XVI. Yüzyılın başından itibaren Hacı Bektaş-1 Veli öğretisi doğrultusunda kurumsallaşma sürecini tamamlamış olduğu kabul edilmektedir. ${ }^{1}$ Başka bir yaklaşımla Bektaşilik, Babai hareketinin bir araya getirdiği heterodoks sufi tarikatlarından biri olan Haydarilik bünyesinde, 14.yüzyıl Rum Abdallarından Abdal Musa tarafindan Hacı Bektaş-1 Veli inancı etrafinda geliştirilmiş ve 16. Yüzyıl başında Balım Sultan tarafından bağımsızlaştırılıp değişik bir organizasyonla, bir tarikat olarak tarih sahnesinde yerini almıştır. ${ }^{2}$

Erkân tarikatın sahip olduğu kuralları, temel ilkeler ve törenler bütününü ihtiva eden bir kavramdır. Tasavvuf ıstılahında sûfilerin uydukları ve uyguladıkları kurallara "adab-1 sufiyye", tarikat ehlinin gözettiği ve dikkate aldığı kurallara da "adab-1 tarikat" veya "âdâb ve erkân" denilmektedir. ${ }^{3}$ Dini grupların bir türü olarak tarikatların, hem dini-sosyal hayatta yaşayabilmeleri hem de varlıklarını devam ettirebilmeleri için birtakım kurallara tâbi olmak mecburiyetleri bulunmaktadır. Bektaşilikte bu kuralların adına genel olarak Erkânnâme adı verilmektedir. Her bir Bektaşî hem yaşamını hem de tarikat içindeki sorumluluklarını bu Erkânnâme çerçevesinde yerine getirmektedir. ${ }^{4}$

Ömer Faruk Teber tarafından yazılan Balkanlar'da Bâbâgân Koluna Ait Bir XIX. Yüzyıl Bektâş̂̂ Erkânnâmesi adlı eserde, önsöz, giriş, iki bölüm, kaynakça ve Hacıbektaş ilçe Halk Kütüphanesi No:36'da kayıtlı Bektaşi Erkânnâmesi metin transliterasyonu yer almaktadır.

Müellif Giriş bölümünde, mezhep kavramını, İslam tarihinde sosyal, siyasi ve ekonomik sebeplerle ve din anlayışındaki farklılaşmaların kurumsallaşması sonucu ortaya çıkan dini nitelikli oluşumlar ve dinin anlaşılma biçimleri ile ilgili tezahürler olarak tanımlamaktadır. Bu tanımlamadan sonra, manevi, ilahi ve ahlaki değerlerin anlaşılmasında mahiyatine uygun tarzda kavramasında ve doğruya en yakın şekilde tesbit edilmesinde nass ve nakli esas alan Selefi anlayışın, akıl, istidlal ve muhakemeyi esas alan Kelami zihniyet, keşf, feyz ve ilhamı esas alan Sufi

\footnotetext{
${ }^{1}$ Ömer Faruk Teber, Bektâşî Erkânnâmelerinde Mezhebî Unsurlar, Ankara 2008, s. 7.

${ }^{2}$ Fazlı Arabac1, Alevilik ve Sünniliğin Sosyolojik Boyutları, Ankara 2009, s. 29.

${ }^{3}$ Ethem Cebecioğlu, Tasavvuf Terimleri ve Deyimleri Sözlüğü, Ankara 1997, s. 83.

${ }^{4}$ Teber, Bektâşî Erkânnâmelerinde Mezhebî Unsurlar, s. 9.
} 
yaklaşımların islam düşünce tarihinde mezhep ve tarikat formunda çeşitli ekol ve akımların vücut bulmasına sebep olduklarını dile getirmektedir. (s. 9).

Teber, Bektaşiliğin, hem Türk düşünce hayatının önemli yapı taşlarından birini oluşturduğunu hem de İslam dünyasında üzerinde çok durulan tarikatların başında geldiğini ifade etmektedir. Erkânnâmelerin de Bektaşiliğin, adap ve erkanının en doğru ve mahiyatine en uygun bir şekilde tespit edilmesinde en özgün ve orijinal bilgi kaynaklarından olduğuna dikkat çekmektedir. Erkânnâmelerin, itikadi ve amali bir takım kuralları ihtiva etmelerinin yanında içeriklerinde ciddi bir sembolizmin olduğuna dair yaptığı vurgu ve bireylerin sosyal hayatlarını düzenleme ve davranışlarına yön verme yazarın önemli tespitleri arasında kabul edilebilir. (S $10)$.

Yazar bu bölümde Bektaşiliğin temel amaçlarından da bahsetmektedir. Ona göre, Bektaşiliğin ana amaçlarından biri "Erdemli Toplum" tesisidir. Bu amacın temel yapı taşı ise erdemli insandır. Erdemli insan olabilmek için de bir eğitime tabii olmak gerekmektedir. Bu eğitimin yol ve yordamını Erkânnâmelerde yazıya dökülmüş kurallar oluşturmaktadır. Söz konusu kurallara göre eğitimini tamamlayan kişi "İnsan-1 Kâmil” mertebesine ulaşmaktadır. Bu eğitimin amacı, faziletli bir toplumu meydana getiren kâmil insanların yetişmesidir. Ona göre, Erkânnâmeler, kaynağını Kur'an ve sünnetten alan bir hayat kılavuzu mesabesinde kabul edilmektedir. (S. 11).

Giriş bölümünde üzerinde durulan bir başka husus da "Dört Kapı Kırk Makam” konusudur. Yazara göre bu esas, Kur'an ve sünnet temelinde inşa edilen tasavvufi bir düşünce, bir eğitim metodudur. Temelleri Hacı Bektaş-1 Velî tarafından atılan bu esas ve usullerin, bir sistem halinde bir araya toplanarak kurumsallaşması II. Bayezid tarafından Dimetoka'dan getirilerek posta oturtulan Balım Sultan iledir.

Birinci bölümde Türkiye Kütüphanelerinde Bulunan Bektaşi Erkânnâmeleri konusu incelenmektedir. Yazar, yazma halde bulunan Bektași Erkânnâmelerinin yazı karekterleri ve ifade tarzı açısından bir bütünlük arz etmediklerini belirtmektedir. Ona göre, Bektaşi geleneği içerisinde yazılan bu eserler, genellikle Bektaşi Babaları ve Dedebabalar tarafından kayıt altına alınarak tarikat mensuplarının istifadesine sunulmuştur. Erkânnâmeleri kayıt altına alan Bektaşi babaları ve Dedebabalarının ölümünden sonra bu eserleri koruma ve tamamlama görevi, Bektaşi dergahı postuna geçen Babalar ve dedebabalara devredilmiştir. (s. $15)$. şunlardır:

Bahsi geçen yazma kaynaklardan yazarın tespit ettiği Erkânnâmeler

a-Hacı Bektaş İlçe Halk Kütüphanesi yazmaları

b- Milli Kütüphane Yazmaları

c- Türkiye Kütüphanelerindeki Erkanname Türü Yazma Nüshalar

d- Yayımlanmış Erkânnâmeler

Erkânnâmelerin kayıt numaraları, hat çeşitleri ve varak sayılarından bahsedilse de içerikleriyle ilgili olarak, Cem ayini içerisinde yapılacak erkan ve bazı tercümanların yer aldığı bilgisi dışında genel olarak yazmaların hangi konudan bahsettiğiyle ilişkili herhangi bir değerlendirme ve bilgilendirme yapılmamıştır.

Araştırmanın ikinci bölümü Bektaşi Erkânnâmesinin Muhtevası adını taşımaktadır. Bu bölüm, İnanç Esasları, İlmihal, Tasavvuf ve Ahlak başlıkları altında incelenmiştir. İnanç Esasları: Yazar Erkânnâmelerin, hem Aleviliğin hem de Bektaşiliğin temel kaynaklarından olduğunu vurguladıktan sonra, bu eserlerin inançamel yörüngesini en sağlıklı bir biçimde izah edecek işlevsel özelliğe sahip olduğunun altını çizmektedir. $\mathrm{Bu}$ bölümdeki önemli tespitlerden birisinin de Bektaşilerdeki Allah sevgisi, bağışlaması ve lütfu inancının hakim durumda olduğu, Bektaşi kaynaklarda Allah'a olan sevgi ve bağışlanma ümidinin, Allah korkusundan daha bariz bir şekilde ifade edildiği konusunun olduğu düşünülmektedir. Yazara göre, pek çok tasavvufi ekol ve tarikatlara ait eserlerde olduğu gibi Erânnâmelerde

Turkish Academic Research Review - Türk Akademik Araştırmalar Dergisi 
de şeriat-tarikat-marifet-hakikat kompozisyonu bir yol olarak benimsenmiștir. Bu izlenen yolda teolojik tartışmalara girilmemiş, müntesiplerin bilmeleri gereken inanç esasları ayrıntıya inilmeden sunulduktan sonra, muhabbetle tanrıya bağlanmayı öğütleyen ve insanlara bu çağrıyı ulaştırma görevi temel anlayış olarak benimsetilmeye çalışılmışıtır.

Tevhit bahsinde, sûfi geleneklerin tevhide sembolik manalar yükledikleri ve rumuzlarla örülmüş bir dini kültürel yapı oluşturdukları dile getirilmiş̧ir. Erkânnâmelerde tıpk1 geleneksel Sünnî kaynaklarda tasnif edildiği gibi Allah'ın sıfatları Zatî ve Subutî olmak üzere iki kategoride ele alınmıştır. Nübüvvet konusunda Erkânâmelerde peygamberlerin gerekliliği ve sıfatları anlatılmıştır. Söz konusu sıfatlar, sıdk, emanet, tebliğ, fetanet ve ismet olmak üzere beş kategoriye ayrılmıştır. Hz. Muhammed'in gelmiş geçmiş peygamberlerin en üstünü olduğu, hem insanlara hem de cinlere gönderilmiş olduğu ifade edilmiş ve bu bilgilerin Müslümanlar tarafından bilinmesinin vacip olduğu vurgulanmıştır. Yine Erkânâamelerde Hz. Muhammed (s.a.v.)'in güzel ahlakı ve üstün özellikleri zikredilerek onun yolundan gidilerek sünnetine riayet edilmesi tavsiye edilmektedir. (s. 27).

Yazarın naklettiğine göre, Erkânâmelerde insanın dünya hayatında yapması ve yapmaması gerekenler anlatılarak bütün bu eylemlerin ahirette nasıl karşılık bulacağı özellikle Kur'ân ayetleri aracılığı ile betimlenmektedir. Yapılan her iyilik ve kötülüğün karşıllğı bulunacaktır. Ölümden sonra kabir hayatı, sur üflenerek yeniden diriliş, mizan kurulup hesaba çekilme, Münker-Nekir'in şahitlikleri ve ardından cennet veya cehenneme götürülmesine ilişkin sahneler gayet canlı bir şekilde anlatılmaktadır. Dünya ve ahiret arasında bir denge kurulmasının gerekliliği üzerinde durulmaktadır.

Teber'in Erkânnâmeler ile ilgili yaptığı diğer önemli tespit de bu eserlerde genellikle Ehl-i Sünnet anlayışının hakim olduğu konusudur. Söz konusu âdâb ve Erkan kitaplarında Caferî mezhebine mensubiyet ifade edilirken, amelde mezhep önderlerinin İmam-1 Azam olduğu sıkça vurgulanmaktadır. (s. 29).

Erkânnâmelerde ilmihal bilgilerine de geniş yer verildiği anlaşılmaktadır. Namaz, oruç, hac, zekat gibi ibadetlerin erkek ve kadına farz olduğu açıkça belirtilmiştir. İbadetlerden en çok üzerinde durulan konu namazdır. Yazarın aktardığına göre, Erkânnâmelerde, ilk önce abdestin ve guslün farzları tek tek sayılmaktadır. Ardından namaz ile ilgili hükümler ve uyulması gereken hususlar anlatılmakta ve namazın nasıl kılınacağı hangi duanın nerede okunacağı ayrıntılı bir şekilde anlatılmıștır.

Erkânnâmelerde tasavvufî boyut üzerinde de durulmuş, Şeriat-TarikatMarifet-Hakikatten oluşan Dört Kapı Kırk Makam vurgusu yapılmaktadır. Hacı Bektaş-1 Veli tarafından oluşturulan bu erkanların Balım Sultan tarafından sistemli hale getirildiği kabul edilmektedir. Şeriat kapısı, İslam dinin temel ilkeleri ve kurallarını ihtiva etmektedir. Tarikat kapısı ise, tarikata intisap etme kural ve kaidelerini bildirmektedir. Marifet kapısı mevcudatın sırrına vukufiyet demektir. Hakikat kapısı ise insanın Hakk'a vasıl olarak kendi benliğinden soyunmasını ifade etmektedir. (s. 33).

Yazara göre, Bektaşiliğin hedeflediği ahlak, mükemmel insanın özellikleridir. İnsan-ı kamildeki tertemiz öz öyle parıldar ki insanın dış dünyasını da aydınlatır. Benlik duygusu insanın özünün temizlenmesinde engeldir. Bu nedenle kalbin benlik kirlerinden arındırılması gerekir. İnsana saygı ve hürmet ise ibadetlerin en büyüğü olarak kabul edilir. Eserde ahlak başlığının altında iki alt başlık bulunmaktadır. Bunlardan birincisi olan ahitnameler başlığında, bir bağlının ne gibi sorumlulukları yerine getirmesi gerektiği belirtilmektedir. Bu gereklilikler on bir madde halinde tespit edilmiştir. İkinci alt başlıkta mürşid mürid ilişkisi ele alınmıştır. Buna göre, Bektaşilikte Ehl-i Beyt sevgisi merkezi bir konum işgal etmektedir. Hz. Muhammed ile Hz. Ali arasındaki mürşid- mürid ilişkisi silsilenin başı kabul edilmektedir. Kamil mürşid olunabilmesi için gerekli dokuz husus

Turkish Academic Research Review - Türk Akademik Araştırmalar Dergisi 
bulunmaktadır. Pirden müride ulaşması gereken on iki nasihat dile getirilmektedir. Müride mürşid tarafından söylenen sözler mürşidin nefsinden kabul edilmez. Mürşitte benlik kalmadığından onun sözleri hak sözüdür. Dolayısıyla da mürid mürşidin emrini her şeyden üstün tutmalıdır. (s. 37).

Tarih boyunca Türklerin fikhın ağır koşulları yerine ruh ve ahlaki davranışlara meyilli hoşgörü temelli din anlayışlarını temsil eden Bektâşîliğin akidevî ve ameli/pratik yönleri bu çalı̧̧mada transliterasyonu yapılan Bektâşî Erkânnâmesi ile ortaya çıkarılmıştır. Eser içerisinde yer alan Transkripsiyon metin, Balkan coğrafyasında Bektâşî tekkelerinde halen okunmakta ve uygulanmakta olan bu erkânlardan günümüze ulaşmış orijinal el yazması bir nüshadan yazar tarafindan çevrilmiştir.

Transliterasyon metin, Bektâşî ayin ve erkânlarında okunan Duvazdahlar, Tercümânlar, Duâ ve niyazları ihtiva etmektedir. Erkânı oluşturan her bir ritüel ve ritüellerde dile getirilen dua ve ilahiler, mersiyeler, Bektâşi Dede ve Babalarının özenle sakladıkları ve bu sayede de Bektâşî düşüncesinin nesilden nesile aktarıldığı geleneğin bizzat yazılı metinleridir. Bu metinlerde ayrıca Ehl-i Beyt mensuplarının ve müntesiplerinin mistik hayatları, İslâm düşüncesinin teşekkül ve tedvin edildiği Sünnî ve Şiî geleneklerin izleri; Hoca Ahmet Yesevî'den Hacı Bektâş-1 Velî’ye kadar gelen Türk kültür tarihinin eserleri sade bir dil ile yine Bektâşî dervişleri tarafindan kaydedilmiş olduğu ifade edilmiştir.

Ekânnâmeler, Bektaşilerin uymaları gereken temel kuralları ihtiva etmesi ve tarikatın ana kaynaklarından olma özelliklerinden dolayı son derece ehemmiyetli kaynaklardır. Bu çalışma böylesine ehemmiyetli bir çalışmayı konu edindiği için takdire şayandır. Ancak Erkânnâmelerin içerikleriyle ilgili yeterli bilgi verilmemesi ve Diğer Erkanname çeşitleriyle herhangi bir karşılaştırmaya gidilmemesi önemli bir eksiklik olarak görülmektedir. Kitapta bir sonuç bölümü de bulunmamaktadır. Dolayısıyla bu çalışmada hangi sonuçlara ulaşıldığı bilgisine ulaşılamamaktadır. Kitabın daha sonraki baskılarında değinilen hususların dikkate alınması önerilmektedir. 